\title{
Spectacle wear and factors associated with non-compliance among children of 5-15 years
}

\author{
Saira Mehnaz ${ }^{1}$, Ziya Siddiqui ${ }^{2}$, Ali Jafar Abedi $^{3}$, M Athar Ansari $^{4}$
}

${ }^{1}$ Associate Professor, Department of Community Medicine, JN Medical College, Aligarh Muslim University, India; ${ }^{2}$ Assistant Professor, Department of Ophthalmology, JN Medical College, Aligarh Muslim University, India; ${ }^{3}$ Assistant Professor, Department of Community Medicine, JN Medical College, Aligarh Muslim University, India; ${ }^{4}$ Professor, Department of Community Medicine, JN Medical College, Aligarh Muslim University, India

\begin{tabular}{|c|c|c|c|c|c|c|c|}
\hline Abstract & Introduction & Methodology & Results & Conclusion & References & $\underline{\text { Citation }}$ & $\underline{\text { Tables / Figures }}$ \\
\hline
\end{tabular}

\section{Corresponding Author}

Ali Jafar Abedi, Department of Community Medicine and Institute of Ophthalmology, JN Medical College, Aligarh Muslim University, India

E Mail ID: alijafarabedi@gmail.com

\section{Citation}

Mehnaz S, Siddiqui Z, Abedi AJ, Ansari MA. Spectacle wear and factors associated with non-compliance among children of 5-15 years. Indian J Comm Health. 2020;32(1):87-90.

Source of Funding: Nil Conflict of Interest: None declared

\section{Article Cycle}

Received: 22/08/2019; Revision: 10/01/2020; Accepted: 20/02/2020; Published:31/03/2020

This work is licensed under a Creative Commons Attribution 4.0 International License.

\section{Abstract}

Introduction: Refractive errors are the commonest cause of visual impairment in school children worldwide. They are correctible and after screening, spectacles can easily enhance vision. This can be achieved only when spectacles are used regularly. Objective: This study was conducted to study the compliance of spectacles wear among children and to determine the reasons associated with non-compliance. Methodology: 400 children in the age group of 5-15 years with refractive errors attending the eye OPD, using spectacles for more than three months were included. Spectacle wear and reasons of noncompliance were enquired. Data was analyzed to determine the factors associated with spectacle wear compliance. Results: Among 232 boys and 168 girls 142 were from rural and 258 from urban areas. 244(61\%) children were compliant. Compliance was better in older children and those from urban areas. Children of educated parents and with power more than -1.0 D were more likely to be compliant. Main reason for not wearing spectacles was 'lost or broken spectacles' and dislike for spectacle. Conclusion: Counselling of parents, teachers and peers will be an effective step towards improvement of compliance of spectacles use.

\section{Keywords}

Spectacle; Compliance; Myopia

\section{Introduction}

Blindness and visual impairment are representing severe public health and socio-economic problems in the world. Visual impairment and its overall effects on development of children including physical and social development, is associated with early correction of refractive error and compliance of spectacles. It was estimated worldwide that 19 million children are visually impaired. Out of these, 12 million children are visually impaired due to uncorrected refractive errors (RE). (1)

Refractive errors are the commonest cause of visual impairment in school children worldwide. WHO launched a global initiative 'VISION 2020: The Right to Sight' to combat the gigantic problem of blindness in the world. Refractive errors are the commonest cause of visual impairment. (2) Refractive errors are correctible and after screening, spectacles or eyeglasses which are frames bearing lenses worn in front of the eyes, can easily enhance vision. This can be achieved only when spectacles are used regularly.

Refractive errors especially myopia is quite common in children and can impair learning.(3) Children who wear spectacles can be prevented from amblyopia and visual impairment but the proportion of children who could benefit from spectacle correction and do not yet wear glasses has been found to be high in studies conducted in India and elsewhere. Very few articles are published in India focusing on reasons of noncompliance of spectacles.(3). 


\section{Aims \& Objectives}

This study was conducted to study the compliance of spectacles wear among children and to determine the reasons/factors associated with non-compliance.

\section{Material \& Methods}

An Out Patient based observational study was conducted over a period of 6 months in the Institute of Ophthalmology and Urban Health Training Centre of Department of Community Medicine of JN Medical College, Aligarh Muslim University, Aligarh.

All the children between 5 to 15 years of age, attending the eye OPD, using spectacles for more than three months and whose parents/guardians consented to participate in the study were included. A predesigned, pretested oral questionnaire was used to elicit information on use of spectacles in Hindi language. Sample size calculated for this study was 384, rounded to 400 . Hypothesized frequency of outcome variable was considered to be $50 \%$, taking 95\% confidence interval and 5\% significance level. Children and parents/guardians were provided with the correct information at the end of the interview. The procedures followed were in accordance with the ethical standards of the responsible committee on human experimentation (Helinski).(4) Data was analyzed using SPSS version 18.0 software. Descriptive statistics (percentages) was used to describe the data, the $\chi 2$ tests was applied to check any statistical association between independent and dependent variables. A p value of 0.05 or less was taken as significant.

The compliance of spectacle wear in relation to time can be accessed through later follow up observations, which was not done in the present study. Therefore, the reported compliance rate may not give the real picture of spectacle wear in the studied population.

\section{Results}

Four Hundred children between 5 to 15 years of age, attending the eye OPD, using spectacles for more than three months were recruited in the study. The study revealed that $244(61 \%)$ children were using the spectacles and 156 (39\%) were non compliant.( Figure 1)

Socio- demographic factors associated with noncompliance are described in Table-1. A significantly higher proportion of children in age group 8-15 years (48.7\%) were compliant to spectacles use as compared to other age group $(p=<0.05)$. compliance rate was also found significantly high in urban children.

Parental education had a positive bearing on spectacle compliance, 134 (54.9\%) of children of educated patients were compliant as compared to $110(45.1 \%)$ in uneducated parents. Similarly, the compliance rate was statistically higher in children whose parents were also using spectacles. It was found that children having RE of less than Two had compliance rate of only $15.6 \%$ whereas in children having RE of Two or more it was $45.1 \%$.
Duration of prescription of spectacles was also a determinant of spectacle wear compliance. The compliance rate was higher in children who had been prescribed for longer duration than those who had been prescribed recently.

The study further tried to analyze the reasons (Table 2) for causes of non-compliance in 98 males (62.8\%) and 58 (37.2\%) females, it was found that breakage of spectacles (14.7) was the commonest reason without any significant difference between genders. $14.1 \%$ children complained of loosing spectacle significantly more in males than females. Social unacceptability and mocking was also a major reason for non-compliance in wearing spectacles and was significantly higher in females. Dislike like to wear spectacle was the reason found in $8.2 \%$ males and $12.2 \%$ females. Some children felt that spectacles are not needed or useful to them like $4.1 \%$ males and $4.5 \%$ females. Students reported they were not comfortable wearing spectacles and some complained of headache while $10.3 \%$ preferred wearing only while studying.

\section{Discussion}

The overall compliance of spectacles wear in the studied population was $61 \%$ which is comparable to study done in South India(5) but relatively higher to $29.5 \%$ among the rural secondary school children in Pune(6) and 19.5\% compliance from rural central India.(7)

In our study the children in older age group (8-15 years) were found to be more compliant than younger age group. A study done in Pakistani children found similar results whereas some other studies have found older children less likely to be compliant than younger ones. The older children better understand the desirability of compliance and their visual needs for serious studies enhanced the compliance among this age group.(1)

Children from urban areas were more likely to show compliance in the present study. This was similar to results observed by Pavithra et al in South India. (5) and Congdon et al. in South Africa where too urban children were more likely to wear their spectacles.(8). This could be that due to better to access to health care urban children get diagnosed for RE and more children wear spectacles in the locality and child may not feel odd wearing spectacles as compared to rural areas.

In our study parental education was found to be a very important contributing factor towards compliance of spectacles among children. Those children whose parents were educated had more awareness related to importance of spectacle wear among children. Studies conducted in India have also shown that children with low father's education were more likely to be non-compliant for spectacle wear than others. $(4,5,6,7)$

The factors that have been found to be associated with wearing spectacles in most of the similar studies were 
higher degree of myopia. $(5,9)$ In the study spectacle compliance was especially low among children with modest degrees of refractive error. The spectacle-wear was significantly associated with power of $-1 \mathrm{D}$ and below ( $p=0.05$ ) where as children with power less than -1D of power were more non-compliant akin to other studies.

The effect of parental spectacle usage on spectacle wear compliance was also studied. It was found that those children whose parents were using spectacles had better compliance. This association was statistically highly significant. Study in Rohtak also had similar results.(3)

The main reasons for non-compliance regarding spectacle use in the present study were lost or broken spectacle. This was significantly higher in boys. Other important reason for non-compliance was the perception that constant use causes dependence. Good number of noncompliant children had disliking for spectacles. In girl children social unacceptability and teasing by peers was an important contributory factor for non-compliance. The results are more or less comparable to other Indian studies. $(3,5)$

\section{Conclusion}

The compliance rate was found to be $61 \%$. The study showed that compliance of spectacles is associated with older age and higher duration of prescription of spectacles.

The reasons of noncompliance include broken / lost spectacles, peer pressure and dislike for spectacles. Counseling of parents and teachers and peers can be an effective step towards improvement of compliance.

A community-based study should be conducted to assess the determinants of the spectacle use and the barriers to spectacle use should be addressed.

\section{Recommendation}

The prevalence of myopia among school-age children is well known to increase with age thus interventions to screen children and prescribe spectacles early is more likely to comply and allow this pattern of better compliance at a later age when the risk of more visually significant refractive error is higher further providing spectacles that are pretty and strong can improve compliance.

\section{Limitation of the study}

[Spectacle-Wear...] | Mehnaz S et al

The major limitations of our study are that the measure of compliance was based only on whether the participants presented wearing eyeglasses in OPD and that many of our results were obtained from participants' self-report. Another limitation of our study is that we did not investigate cultural attitudes about spectacle wear which could reveal many other reasons.

\section{Relevance of the study}

The study provides insight to compliance and barriers to spectacle use among children

\section{Authors Contribution}

All authors have contributed equally

\section{References}

1. Ishtiaq Anwar, Saman Waqar, Anam Altaf, Compliance of Spectacle Wear Among School Going Children in District Rawalpindi, Pakistan, International Journal of Ophthalmology \& Visual Science. Vol. 2, No. 1, 2017, pp. 1-4. doi: 10.11648/j.ijovs.20170201.11

2. World Health Organization. Universal Eye Health: a global action plan 2014-2019 [Internet]. World Health Organization. 2013. [[cited 2019 Jun 20]]. Available from: http://www.who.int/blindness/AP2014_19_English.pdf?ua=1.

3. Morgan IG, Ohno-Matsui K, Saw SM. Myopia. Lancet. 2012;379:1739-48

4. Bhatt NK, Rathi M, Dhull CS, Sachdeva S, Phogat J. Spectacle compliance amongst school children of Rohtak, Haryana, India. Int J Community Med Public Health. 2017;4(3):734-737. doi:10. 18203/2394-6040.ijcmph20170749

5. World Medical Association Declaration of Helsinki: ethical principles for medical research involving human subjects. Postgrad Med 2002;48:206

6. Pavithra MB, Hamsa L, Madhukumar S. Factors associated with spectacle-wear compliance among school children of 7-15 years in South India. Int J Med Public Health. 2014;4:146-50.

7. Gogate P, Mukhopadhyaya D, Mahadik A, Naduvilath TJ, Sane S, Shinde $A$, et al. Spectacle compliance amongst rural secondary school children in Pune district, India. Indian J Ophthalmol 2013;61:8-12.

8. Chawla K, Rovers J. Survey of Patient Opinions on Eyeglasses and Eye Care in Rural and Slum Populations in Chennai. Internet $J$ Epidemiol [Internet]. 2009 Dec 31 [cited 2019 July 3]; 8(2). Available from: http://ispub.com/IJE/8/2/13165.

9. Congdon NG, Patel N, Esteso P, Chikwembani F, Webber F, Msithini $\mathrm{RB}$, et al. The association between refractive cutoffs for spectacle provision and visual improvement among school-aged children in South Africa. Br J Ophthalmol 2008 ;92:13-8

10. Khandekar R, Sudhan A, Jain BK, Tripathy R, Singh V. Compliance with spectacle wear and determinants in school students in central India. Asian J Ophthalmol 2008 ;10:174-7.

\section{Tables}

\begin{tabular}{|c|c|c|c|c|}
\hline \multirow[t]{2}{*}{ Variables } & \multicolumn{2}{|c|}{$\begin{array}{ll}\text { Outcome } \\
\end{array}$} & \multirow[t]{2}{*}{ Total } & \multirow{2}{*}{$\begin{array}{c}\text { p- Value } \\
\left(x^{2}\right)\end{array}$} \\
\hline & No compliance (\%) 156 & Compliance (\%)244 & & \\
\hline \multicolumn{5}{|l|}{ Age in years } \\
\hline $5-7$ & $48(30.8)$ & $56(23.0)$ & $104(26.0)$ & \multirow{3}{*}{$\begin{array}{l}<0.05 \\
(10.3)\end{array}$} \\
\hline $8-11$ & $76(48.7)$ & $102(41.8)$ & $178(44.5)$ & \\
\hline $12-15$ & $32(20.5)$ & $86(35.2)$ & $118(29.5)$ & \\
\hline \multicolumn{5}{|l|}{ Gender } \\
\hline Female & $58(37.2)$ & $110(45.1)$ & $168(42.0)$ & \multirow{2}{*}{$\begin{array}{l}0.11 \\
(2.4)\end{array}$} \\
\hline Male & $98(62.8)$ & $134(54.9)$ & $232(58.0)$ & \\
\hline \multicolumn{3}{|l|}{ Region } & & \\
\hline
\end{tabular}


INDIAN JOURNAL OF COMMUNITY HEALTH / VOL 32 / ISSUE NO 01 / JAN - MAR 2020

\begin{tabular}{|c|c|c|c|c|}
\hline Rural & $84(53.8))$ & $70(28.7)$ & $142(35.5)$ & $<0.05$ \\
\hline Urban & $72(46.2$ & $174(71.3)$ & $258(64.5)$ & $(25.4)$ \\
\hline \multicolumn{5}{|l|}{ Parental education } \\
\hline Illiterate & $108(69.2)$ & $110(45.1)$ & $158(39.5)$ & \multirow{2}{*}{$\begin{array}{l}<0.05 \\
(22.4)\end{array}$} \\
\hline Educated & $48(30.8)$ & 134(54.9) & $242(60.5)$ & \\
\hline \multicolumn{5}{|l|}{ Parent's using specs } \\
\hline Yes & $76(48.7)$ & $174(71.3)$ & $250(62.5)$ & \multirow{2}{*}{$\begin{array}{l}<0.05 \\
(20.7)\end{array}$} \\
\hline No & $80(51.3)$ & $70(28.7)$ & $150(37.5)$ & \\
\hline \multicolumn{5}{|c|}{ Power of the eyes in diopters ( in any or both eyes) } \\
\hline$<-1.0 \mathrm{D}$ & $76(48.7)$ & $38(15.6)$ & $96(24.0)$ & \multirow{3}{*}{$\begin{array}{l}<0.05 \\
(22.0)\end{array}$} \\
\hline-1 to $-2 D$ & $58(37.2)$ & $96(39.3)$ & 172(43.0) & \\
\hline More than $-2 \mathrm{D}$ & $22(14.1)$ & $110(45.1)$ & $132(33.0)$ & \\
\hline \multicolumn{5}{|c|}{ Duration of prescription } \\
\hline Less than 6 months & $48(30.8)$ & $56(23.0)$ & $104(26.0)$ & \multirow{3}{*}{$\begin{array}{l}<0.05 \\
(19.4)\end{array}$} \\
\hline 6 months to a year & $76(48.7)$ & $86(35.2)$ & $118(29.5)$ & \\
\hline More than a year & $32(20.5)$ & $102(41.8)$ & $178(44.5)$ & \\
\hline
\end{tabular}

\section{TABLE 2 SELF-REPORTED REASONS FOR NON-COMPLIANCE WITH SPECTACLE WEAR}

\begin{tabular}{|c|c|c|c|c|}
\hline REASONS OF NON-COMPLIANCE & $\begin{array}{l}\text { BOYS } \\
\text { NO. (\%) }\end{array}$ & $\begin{array}{l}\text { GIRLS } \\
\text { NO. (\%) }\end{array}$ & Total & $\begin{array}{l}p \text {-Value } \\
\left(x^{2}\right)\end{array}$ \\
\hline 1. Lost/ broken the spectacles & 19(19.4) & $3(5.2)$ & $22(14.1)$ & $<0.05(7.7)$ \\
\hline 2. Constant use causes dependence & $15(15.3)$ & $5(8.6)$ & $20(12.8)$ & $0.3(2.4)$ \\
\hline 3. Uses spectacles while studying & $12(12.2)$ & $4(6.9)$ & $16(10.3)$ & $0.4(1.9))$ \\
\hline 4. Socially unacceptable & $4(4.1)$ & $10(17.2)$ & $14(9.0)$ & $<0.05(5.2)$ \\
\hline 5. Mocked about spectacle & $4(4.1)$ & $12(20.7)$ & $16(10.3)$ & $<0.05(7.5))$ \\
\hline 6. Disliking for spectacle & $8(8.2)$ & 11(19.0) & $19(12.2)$ & $0.07(2.1)$ \\
\hline 7. Spectacles cause headache & $7(7.1)$ & $2(3.4)$ & $9(5.8)$ & $0.4(1.5)$ \\
\hline 8. Uncomfortable and Cumbersome & $7(7.1)$ & $3(5.2)$ & $10(6.4)$ & $0.7(0.6)$ \\
\hline 9. Don't feel spectacles are needed & $4(4.1)$ & $3(5.2)$ & $7(4.5)$ & $0.7(0.02)$ \\
\hline
\end{tabular}

\section{Figures}

\section{FIGURE 1COMPLIANCE TO SPECTACLE -WEAR IN CHILDREN}

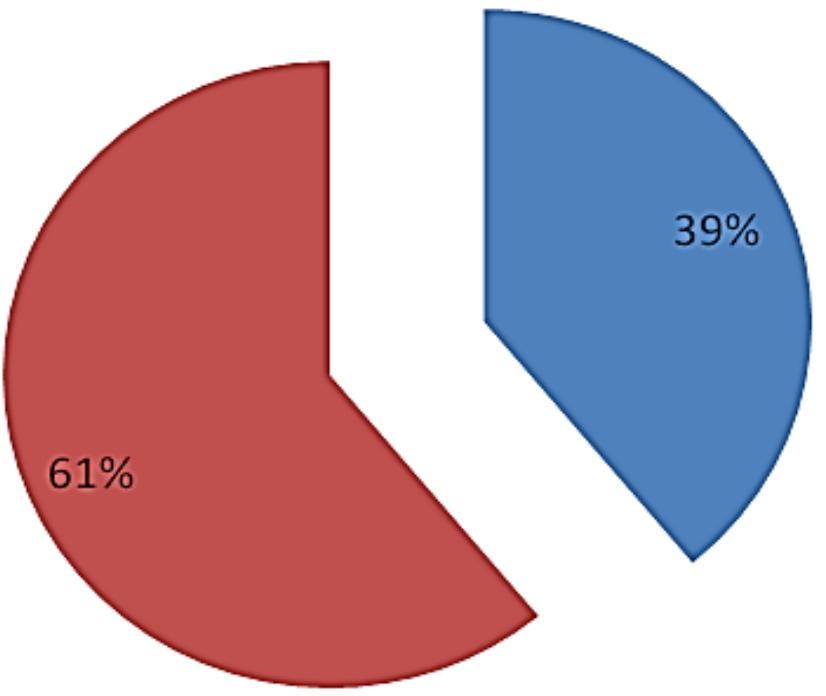

No compliance

Compliance 